\title{
CORRESPONDENCE.
}

\section{ON THE RELATION BETWEEN THE HEIGHT AND WEIGHT OF MEN.}

\section{To the Editor of the Journal of the Institute of Actuaries.}

SrR,--The following statistics regarding the weight of the human body, and the effect which various influences have on it, may be interesting to your readers. They are founded on 2,000 cases taken from the records of a Canadian life company. This number was chosen as sufficient to give reliable results, without increasing needlessly the amount of labour.

Although I am acquainted with several tables purporting to show the average weight corresponding to various heights, $I$ have been unable to find on what basis any one of them rests. Some differ very greatly from others. It thus became a question by what table should a company be guided. To solve the matter I made an investigation, and give herewith the results, with very slight adjustment. Only healthy English-speaking lives were included.

\section{Average Weight at various Heights.}

\begin{tabular}{|c|c|c|c|}
\hline Height. & Weight, & Height. & Weight. \\
\hline 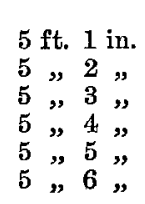 & $\begin{array}{l}\text { 1bs. }=\text { st. } 1 \text { lbs. } \\
125^{\circ}=83^{\circ} \\
128^{\circ}=92^{\circ} \\
131^{\circ}=95^{\circ} \\
134^{\circ}=9 \quad 8^{\circ} \\
137 \cdot 5=9 \quad 17^{\circ}=9 \\
141^{\circ}=10 \quad 1^{\circ}\end{array}$ & 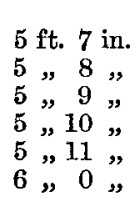 & $\begin{array}{l}\text { lbs. } \text { st. lbs. } \\
145 \cdot 5=10 \quad 5 \cdot 5 \\
151 \cdot 5^{\circ}=10 \quad 11 \cdot \\
156 \cdot 5=11 \quad 2 \cdot 5 \\
161 \cdot 5=11 \quad 7 \cdot 5 \\
167 \cdot=11 \quad 13 \cdot \\
175^{\circ}=125 .\end{array}$ \\
\hline
\end{tabular}

The average height of adult Canadians of British extraction was found to be 5 feet $8 \cdot 6$ inches, and their average weight $155^{\circ} 0$ lbs. The French cases were kept separate, and their average height was found to be 5 feet 7.3 inches, and their weight $149.9 \mathrm{lbs}$. French Canadians are, therefore, as a rule, about one and one-third inches under the English standard in height, and five pounds under it in weight. They are, however, generally heavier than English people of the same height.

The declined lives were also kept separate. Taking into consideration only those cases in which the cause of rejection was a tendency to lung disease of any kind, whether manifested in the applicant personally or in his family history, it was seen that, although their average height was exactly the same as that of the healthy cases, their average weight was only $147 \cdot 6 \mathrm{lbs}$.- -about seven and one-half pounds under the healthy standard. Some such result was expected, and it but confirms the rule that light weight generally accompanies a consumptive tendency. The other rejected cases exhibited nothing remarkable. 
The influence of age is considerable, as may be seen from the following table:-

Weight at various Ages.

\begin{tabular}{|c|c|c|c|}
\hline Ages. & Weight. & Ages. & Weight. \\
\hline $\begin{array}{l}16 \text { to } 20 \\
21 \Rightarrow 25 \\
26 \Rightarrow 30 \\
31 \Rightarrow 35 \\
36 \Rightarrow 40\end{array}$ & 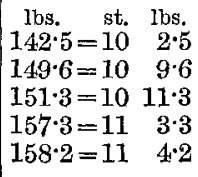 & $\begin{array}{l}41 \text { to } 45 \\
46, " 50 \\
51,55 \\
56,60\end{array}$ & 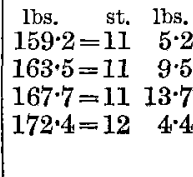 \\
\hline
\end{tabular}

The weight of healthy persons thus increases about thirty pounds in forty years, or about three-fourths of a pound for each year. By far the largest increase is at the younger ages. Whether this rule of increase holds good much after sixty, I have no means of knowing. It is, however, evident that a young man may be considerably under the tabular weight for his height and still be perfectly healthy, while the same variation, in an elderly man, would be very suspicious.

We have already seen that a consumptive tendency and a spare habit of body, generally go hand in hand. As weight is found to increase with age, we may, perhaps, infer that the liability to consumption is less among lives selected late in life, than among those entering at an early age, although the deaths from that disease are pretty evenly distributed over the ages, among assured lives as a class.

The influence of occupation is next to be considered. The following table shows the main results on this score:-

Average Weight of Persons engaged in various Occupations.

\begin{tabular}{|c|c|c|c|}
\hline Occupation. & Weight. & Occupation. & Weight. \\
\hline Agents, Brokers, \&c. & $\begin{array}{ccc}\text { lbs. } & \text { st. } & \text { Ibs. } \\
156 \cdot 2=11 & 2 \cdot 2\end{array}$ & Founders and Moulders & $\begin{array}{c}\text { lbs. } \\
151 \cdot 3=10 \text { lbs. } \\
11 \cdot 3\end{array}$ \\
\hline Butchers . & $169 \cdot 3=12 \quad 1 \cdot 3$ & Hotel-keepers, \&c. . & $166 \cdot 7=1112 \cdot 7$ \\
\hline Barristers . . & $160 \cdot 1=11$ & Labourers . & $148 \cdot 3=10 \quad 8 \cdot 3$ \\
\hline Bankers, Ins.Managers,\&e. & $154 \cdot 2=11$ & Merchants & $153 \cdot 7=1013.7$ \\
\hline Blacksmiths . . & $155 \cdot 4=11$ & Machinists . . & $153 \cdot 5=10 \quad 13 \cdot 5$ \\
\hline Clerks and Salesmen & $147 \cdot 1=10$ & Masons, Bricklayers, \&c. & $162 \cdot 2=11 \quad 8 \cdot 2$ \\
\hline Carpenters, Coopers, \&c. & $152 \cdot 6=1012 \cdot 6$ & Manufacturers & $151 \cdot 1=1011 \cdot 1$ \\
\hline Commercial Travellers & $158 \cdot 1=11 \quad 4 \cdot 1$ & Shoemakers and Saddlers & $148^{\circ} 0=10 \quad 8^{\circ}$ \\
\hline Clergymen . . & $163 \cdot 7=11$ & Teachers. . , & $151 \cdot 4=10 \quad 11 \cdot 4$ \\
\hline Druggists & $148 \cdot 1=10$ & Tailors . & $145 \cdot 1=10 \quad 5 \cdot 1$ \\
\hline Doctors . & $160 \cdot 6=11$ & & \\
\hline Farmers . & $160 \cdot 9=11$ & TotaL . & $155^{\circ} 0=11$ \\
\hline
\end{tabular}

As these statistics are based exclusively on Canadian data, they may be compared with those of other countries, and I will be much 
pleased to see this done. It must be remembered, however, that the average age at entry should be taken into consideration. In the company referred to it is 28 years.

Montreal,

Yours truly, 21 October 1880.

T. B. MACAULAY.

P.S.-Since writing the above, I have noticed in Dr. Allen's Examinations in Life Insurance, a statement to the effect that the average height of Continental Europeans is a little less than 5 feet 6 inches; that of emigrants from Great Britain, about 5 feet 7 inches; and that of Americans, about 5 feet 8 inches. We have seen that the average of English-speaking Canadians is over 5 feet $8 \frac{1}{2}$ inches. If Dr. Allen is correct, he strongly confirms the opinion I have always held, that Canadians are a hardier, better developed, and more muscular race of men than can be found in almost any other country.

A valued correspondent writes to us on the subject of $\mathrm{Mr}$. Macaulay's letter :-

The circumstances of age, occupation, race, season, \&c., are so various, that tables constructed like Macaulay's, Quetelet's, Hutchinson's, and others, on the basis of observations made on a particular class of men, must be expected to give discordant results.

The table [printed below] which I am accustomed to regard as the model for men at the age of (say) 30 years, is constructed on the principles laid down by Mr. Brent, and explained many years ago, in a work on "Corpulence", by the late Dr. Chambers, of London. It assumes that the proportions of an ancient statue (say the Fighting Gladiator) are the correct thing, that the specific gravity of the human body is the same as that of water, and that the cubes of homologous dimensions are in the proportion of the weights; and six per-cent for clothes is added to the weight calculated for the displacement of water by a body built on such a model. The resulting formula is $\mathrm{W}=\frac{h^{3}}{2,000}$, where $h$ is the height in inches and $\mathrm{W}$ the weight in pounds.

When a man's weight exceeds or falls short of the standard according to the table, by (say) 15 per-cent, I consider he is not a well-proportioned man, and in case of his life being proposed for assurance, such divergence from the standard of ideal perfection should be seriously considered as a possible ground for the application of extra premium. 
Table of Proportions between Height and Weight of Healthy Men.

\begin{tabular}{|c|c|c|c|c|c|c|c|}
\hline \multirow{4}{*}{$\begin{array}{l}\text { HetaHT. } \\
\text { Inches. } \\
63^{\circ}\end{array}$} & \multirow{2}{*}{\multicolumn{2}{|c|}{$\begin{array}{c}\text { WEIGHT. } \\
\text { Model. }\end{array}$}} & \multirow{2}{*}{\multicolumn{2}{|c|}{$\frac{\text {-WEIGHT. }}{\frac{1}{3} \text { th too little. }}$}} & \multirow{2}{*}{\multicolumn{2}{|c|}{$\frac{+ \text { WEIGHT. }}{\text { sth too much. }}$}} & \multirow{2}{*}{ HEIGHT } \\
\hline & & & & & & & \\
\hline & lbs. & st lbs. & lbs. & st. lbs. & lbs. & st. lbs. & ft. in. \\
\hline & 125 & 813 & 104 & 76 & 146 & 106 & 53 \\
\hline $63 \cdot 5$ & 128 & 92 & 107 & 79 & 149 & 109 & $5 \quad 3.5$ \\
\hline 64 & 131 & & 109 & 711 & 153 & 1013 & $5 \quad 4$ \\
\hline $64 \cdot 5$ & 134 & 98 & 112 & 80 & 156 & 112 & $54 \cdot 5$ \\
\hline 65 & 137 & 911 & 114 & 82 & 160 & I1 6 & 55 \\
\hline 65.5 & 141 & 101 & 117 & 8 & 165 & 1111 & $5 \quad 5.5$ \\
\hline 66 & 144 & 104 & 120 & 88 & 168 & 120 & 56 \\
\hline 66.5 & 1417 & 107 & 122 & 810 & 172 & 124 & $5 \quad 6.5$ \\
\hline 67 & 150 & 1010 & 125 & 813 & 175 & 127 & 7 \\
\hline $67 \cdot 5$ & 154 & 110 & 128 & 92 & 180 & 1212 & 57.5 \\
\hline 68 & 157 & 11 & 131 & $9 \overline{5}$ & 183 & 131 & 58 \\
\hline $68 \cdot 5$ & 161 & 117 & 134 & 98 & 188 & 136 & 8.5 \\
\hline 69 & 164 & $11 \quad 10$ & 137 & 911 & 191 & 139 & 9 \\
\hline $69 \cdot 5$ & 168 & 120 & 140 & 100 & 196 & 140 & $5 \quad 9 \cdot 5$ \\
\hline 70 & 172 & 124 & 143 & 103 & 201 & 145 & 510 \\
\hline $70-5$ & 176 & 128 & 147 & 107 & 205 & 149 & 510.5 \\
\hline 71 & 179 & 1211 & 149 & 109 & 209 & 1413 & 511 \\
\hline $71 \cdot 5$ & 183 & 131 & 152 & 1012 & 214 & $15 \quad 4$ & 511.5 \\
\hline 72 & 187 & 135 & 156 & 112 & 218 & 158 & \\
\hline $72 \cdot 5$ & 191 & 139 & 159 & 115 & 223 & 1513 & $\begin{array}{ll}6 & 0.5\end{array}$ \\
\hline 73 & 195 & 1313 & 162 & 118 & 228 & 164 & 61 \\
\hline 73.5 & 199 & 143 & 166 & 1112 & 232 & 168 & $\begin{array}{ll}6 & 1 \cdot 5\end{array}$ \\
\hline 74 & 203 & 147 & 169 & 121 & 237 & 1613 & 62 \\
\hline $74 \cdot 5$ & 207 & 1411 & 172 & 124 & 241 & $17 \quad 3$ & $6 \quad 2 \cdot 5$ \\
\hline 75 & 211 & 151 & 176 & 128 & 246 & 178 & 63 \\
\hline $75 \cdot 5$ & 215 & 155 & 179 & 1211 & 251 & 1713 & $\begin{array}{ll}6 & 3.5\end{array}$ \\
\hline 76 & 219 & 159 & 182 & 130 & 256 & 184 & $6 \quad 4$ \\
\hline
\end{tabular}

We are inclined to question the correctness of the principle adopted in the calculation of this "model" weight, that the bulk and weight of a man increase as the cube of the height, or that in well-built men of all heights, the breadth is proportional to the height. We believe that tall men are generally slighter, and short men stouter, in proportion, than men of middle height; and a comparison of Mr. Macaulay's figures with those in the other table supports this opinion. Mr. Hutchinson's table is printed in vol. i, p. 88, of this Journal, in an extract from Dr. Chambers's work on Corpulence.-ED. J.I.A. 